\title{
Original
}

\section{Bone-Healing Pattern on Critical-Sized Defects Treated by rhPTH}

\author{
María V. Jammal, ${ }^{1,2)}$, Nina F. Pastorino ${ }^{1)}$, Carlos M. Abate ${ }^{2)}$, Shin Takagi ${ }^{3)}$, \\ Hitoshi Nagatsuka ${ }^{4)}$ and Liliana R. Missana ${ }^{1,2)^{*}}$ \\ 1) Laboratory of Experimental Pathology and Tissue Engineering, Oral Pathology Department, Dental School, Tucumán University, \\ Tucumán, Argentina \\ 2) PROIMI-Biotechnology, CONICET, Pilot Plant for Microbial Industrial Processes \& Biotechnology, Tucumán, Argentina \\ 3) Department of Oral and Maxillofacial Reconstructive Surgery, Graduate School of Medicine, Dentistry and Pharmaceutical \\ Sciences, Okayama University, Okayama, Japan \\ 4) Department of Oral Pathology and Medicine, Graduate School of Medicine, Dentistry and Pharmaceutical Sciences, Okayama \\ University, Okayama, Japan
}

(Accepted for publication, July 15, 2012)

\begin{abstract}
Intermittent Recombinant Human Parathyroid Hormone (rhPTH 1-34) is an effective treatment for improving bone mass in patients with osteoporosis; however, its effects on bone regeneration are still unclear. The objective of this study was to evaluate the potential toxicity systemic rhPTH, as well as its ability to regenerate critical-sized defects (CZD) in bone. We used 43 female Wistar rats (body weight, $150 \pm 50 \mathrm{~g}$ ). Critical-sized bone defects in rat calvaria received vehicle alone (Control Group, CG) or daily rhPTH (20 $\mu$ g/ $\mathrm{Kg}$ /day) by subcutaneous injection (Experimental Group, EG). We evaluated bone healing obtained at the 1st, 3rd, and 6th wks post-surgery by biochemical, soft x-ray, histological, and morphometric studies. In the EG, at the 1st and 3rd wks, many areas of focal osteoblast hyperplasia were found on parietal bone. At the 3rd wk, woven and/or lamellar bone, in an organized interconnected trabecular network, showed disrupted mineralization. At the 6th wk, looped bone was found to have formed patterns on parietal bone. New bone formed in the EG showed significant statistical differences $(\mathrm{p}=0.023)$ at the 6th wk. Systemic rhPTH at the dose of $20 \mu \mathrm{g} / \mathrm{Kg} /$ day was able to stimulate bone formation on rat CZD. Also, pre-existing and new bone showed non-proliferative forms of bone hyperostosis (increased non-neoplastic bone).
\end{abstract}

Key Words: rhPTH, Critical-sized defect, Bone regeneration, Proliferative bone lesions, Bone hyperostosis.

\section{Introduction}

Endogenous Parathyroid Hormone (PTH 1-84) plays a key role in calcium homeostasis and bone metabolism ${ }^{1)}$. A continuous measure of exogenous PTH increases bone resorption, whereas its periodic administration stimulates new bone formation ${ }^{2)}$. Increased osteoblast numbers have been shown in adult rats after daily PTH administration, by the proliferation of osteoprogenitors from lining cell differentiation ${ }^{3)}$. Moreover, PTH stimulates osteoprogenitor cell proliferation and differentiation from bone marrow. PTH binds osteoblast and osteocyte receptors and influences increased expression of early genes (c-fos, c-myc, cjun, and IL-6) involved in cell proliferation ${ }^{4}$ ). Also, in vitro, PTH showed a mitogenic effect mediated by transforming growth factor $\beta(\operatorname{TGF} \beta)^{5)}$. Moreover, improved insulin growth factor-I synthesis and secretion from osteoblast-like cells have been demonstrated ${ }^{6}$.

Correspondence to: Liliana Raquel Missana PhD \& DDS. Head Professor, Pje Leopoldo Lugones 80, $\mathrm{B}^{\circ}$ Ojo de Agua, (T4000MFB) Tucumán, Argentina, Tel: +54 3814356428 Fax: +54 3814344448 e-mail: liliana.missana@gmail.com
In 2002, recombinant human parathyroid hormone (rhPTH 1-34) was approved by the US Food and Drug Administration (FDA) for osteoporosis treatment. It has the same $\mathrm{N}$-terminal amino acid sequence-biologically active region-as full-length Human Parathyroid Hormone ${ }^{7}$. It is assumed that the biological activity of intact PTH (hPTH 1-84) resides in the N-terminal sequence; many studies have used the 34-amino-acid peptide hPTH(1-34), now named "Teriparatide". In contrast, Hodsman et al. ${ }^{8)}$ reported that it is conceivable that whole PTH may have slightly different biological actions compared with those of Teriparatide. The aim of this study was to determine the capacity of rhPTH, administered systemically, to regenerate critical-sized defects in bone. Of the limited research available, none addresses the action of Teriparatide. In this regard, Nozaka et al. ${ }^{9)}$ used PTH 1-34 in osteoporotic animals with non-critical-sized bone defects, and demonstrated enhanced bone repair in tibial osteotomies. Komatsu et al. ${ }^{10)}$ had similar results in femoral circular defects. Bone models in normal animals with critical-sized defects (CZD) are selected for the study of bone therapies, because such defects are 
unable to heal spontaneously ${ }^{11,12,13,14)}$ treated subcutaneously with intermittent PTH (1-34), combined with osteoconductive replacement material, polytetrafluoroethylene, and $\beta$ tricalcium phosphate scaffolds, respectively, showed enhanced mechanical strength and increased bone deposition. However, the systemic administration of rhPTH without matrices for the treatment of critical-sized defects remains to be elucidated. In this regard, whether rhPTH induces de novo bone formation has not been demonstrated. Therefore, we hypothesized that the intermittent systemic administration of $\mathrm{rhPTH}, 20 \mu \mathrm{g} / \mathrm{Kg} / \mathrm{day}$, induced bone formation on CZD to repair large bone defects.

\section{Materials and Methods}

\section{Animals}

Forty-three female Rattus norvegicus var. Wistar rats (150 \pm 50 g), approximately 9 wks old, were obtained from the Animal Research Center (Medical School, Tucumán University, Argentina). Animals were housed in pairs, in a specific pathogenfree environment, with a temperature of $22.4^{\circ} \mathrm{C}$ to $23.8^{\circ} \mathrm{C}$, relative humidity of $45 \%$ to $62 \%$, and a 12 -hour light-dark cycle. A standard commercial diet and tap water were available ad libitum. During the study, animals were handled in accordance with the Guide for the Care and Use of Laboratory Animals $8^{\text {th }}$ Edition (National Research Council, 2011) from the National Academies Press (Washington, DC, USA). and The current examination was performed under the guidelines for use of experimental animals with permission of the Animal Experimental Committee of Okayama University.

\section{Experimental design}

The research protocol was submitted to and approved by the local Ethical Committee for Animal Research (Tucumán National University \& CONICET). Critical-sized defects were created in calvariae as previously described ${ }^{11,12}$. Briefly, defects were created manually with the use of a 5-mm-diameter ad hoc punch with smooth edges. Animals were randomly assigned to one of two groups: (A) The Control Group (CG-18n) received only vehicle (saline solution), and (B) the Experimental Group (EG- 25n) was treated with $20 \mu \mathrm{g} / \mathrm{kg} /$ day of rhPTH (Forteo-Teriparatida, Eli Lilly) via subcutaneous injection. The dose used in this study was based on Vahle et al. ${ }^{15)}$ who demonstrated that rhPTH 5-30 $\mu \mathrm{g} / \mathrm{kg} / \mathrm{day}$ was able to induce bone formation without side-effects. After 1, 3 , or 6 wks post-surgery, animals were killed, and bone samples were obtained, fixed in $20 \%$ buffered formalin phosphate for 24 hrs, and stored in $70 \%$ alcohol prior to analysis.

\section{Assays for serum concentration of rhPTH and bone metabolic markers}

At $10 \mathrm{~min}, 60 \mathrm{~min}$, and $24 \mathrm{hrs}$ after subcutaneous rhPTH injection, blood samples were collected from six animals and placed in ethylenediaminetetraacetic acid (EDTA) tubes, to determine the rhPTH plasma levels by human electrochemiluminescence immunoassay. From all animals, blood samples were obtained by tail bleeding and analyzed for total alkaline phosphatase (ALP), tartrate-resistant acid phosphatase (TRAP), and serum calcium. Urine samples were collected by metabolic cages through $24 \mathrm{hrs}$ for identification of calcium levels

\section{Soft X-ray by high-resolution films}

All samples were subjected to soft x-rays with high-resolution Kodak film (mammography type, 18 x $23 \mathrm{~cm}$; GBA Mamograf HF Digital brand equipment, Buenos Aires, Argentina). Exposure time was $0.8 \mathrm{sec}$, at $27.5 \mathrm{kV}$ and $7.0 \mathrm{~mA}^{16}$.

\section{Histopathology}

The specimens were decalcified with modified Morse solution (Okayama University Dental School) and embedded in paraffin in a routine manner. A serial 4- $\mu \mathrm{m}$ central section per defect was selected and stained with Hematoxylin \& Eosin (H\&E), MassonGoldner, Periodic-Acid Schiff (PAS), Roque's trichrome, or Sudan Black, and examined by light microscopy. A single pathologist evaluated all tissues. Subsequently, another pathologist performed an independent review to verify the microscopic observations. The reported results reflect the mutually-agreed-upon diagnoses by both pathologists, last certified by the Argentina Health Ministry ( $\left.\mathrm{N}^{\circ} 31455\right)$. The terminology and diagnostic criteria used to interpret the bone lesions were consistent with the Standardized System of Nomenclature and Diagnostic Criteria Guides for Toxicologic Pathology ${ }^{17}$. The criteria used to classify proliferative changes in bones were based on those used in the Teriparatide study ${ }^{15,18)}$.

\section{Histometric studies}

Photomicrographs were taken from slides from each specimen by means of a Sony digital camera adapted to an Olympus CH30 microscope. The photos obtained by Soft Pinnacle Studio 9.4 with 116.7X magnification were evaluated by Image Pro Plus Version 4.5.0.29 (Windows 1998/NT/2000, 1993-2001, Media Cybernetics, Inc.). A total area of CZD and $2 \mathrm{~mm}$ of surrounding parietal bone was determined. The parameters selected were: parietal bone thickness (from periosteal, pre-existing, and endosteal bones) at 300 pixels from the edge of CZD, evaluated in $\mu \mathrm{m}$; and new bone formed at the edges and center of CZD, expressed as a percentage of the total defect area.

\section{Statistical analysis}

Data are presented as mean \pm standard deviation, as indicated in the Figs. Biochemistry and histomorphometry results were evaluated by the Mann-Whitney test ( $p<0.05)$. 
María V. Jammal et al.: Bone Formation on CZD by rhPTH 1-34

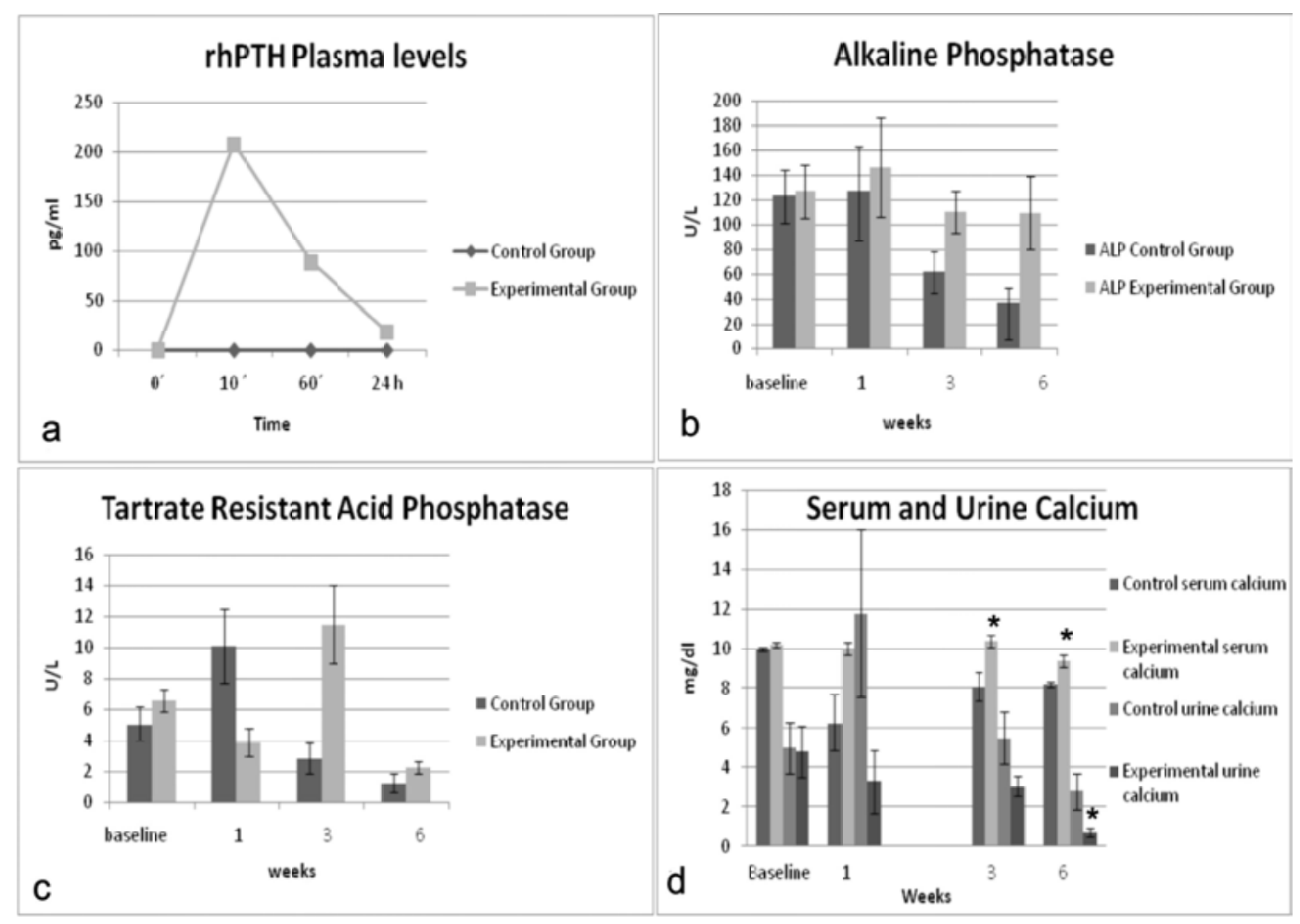

Figure 1. rhPTH plasma levels (a) through one day after a single subcutaneous injection (mean values). rhPTH effect on bone metabolic markers. ALP (b) values showed a significant increase at the $1 \mathrm{st}$, 3rd, and 6 th wks with rhPTH treatment. TRAP (c) values showed a further decrease at the $1 \mathrm{st}$ wk, although there was an increase at the $3 \mathrm{rd}$ wk, and at the 6th wk, the values decreased again. There was no statistically significant difference between groups at both markers ( $<<0.005$, Mann-Whitney test). Serum calcium levels increased through all study periods, and renal excretion decreased relative to urine calcium (d). Data subjected to statistical analysis showed differences from serum calcium levels at all study periods $(\mathrm{p}=0.01,0.02$, and 0.04 , respectively), as well as urine calcium at 6 wks $(\mathrm{p}=0.04)$, indicated by $*(\mathrm{p}<0.05$, Mann-Whitney test $)$.
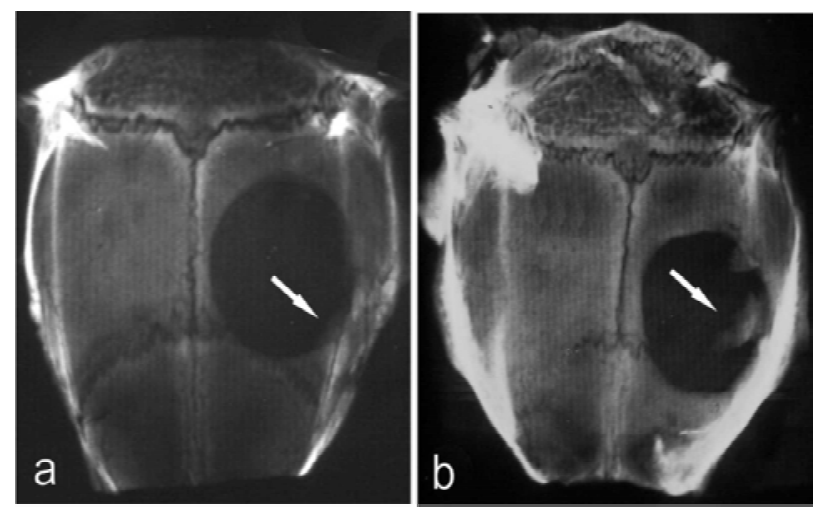

Figure 2. Images of soft $\mathrm{x}$-ray in high resolution at $6 \mathrm{wks}$, showing 5 -mm critical-sized defect diameter, with rounded lytic shadows at the margin. Inside, amorphous opacities can be seen on CZD edges. Control (A) and experimental (B) groups. Magnification 30x.

\section{Results}

\section{Concentrations of serum rhPTH}

Serum levels of rhPTH increased immediately after a single subcutaneous injection, and maximum value was higher than 207.9 $\mathrm{pg} / \mathrm{mL}$ at $10 \mathrm{~min}$, decreasing to $89.2 \mathrm{pg} / \mathrm{mL}$ at $1 \mathrm{hr}$, and to $18.8 \mathrm{pg} /$ $\mathrm{mL}$ at 24 hrs (Fig. 1A).

\section{Bone metabolic markers}

The variations from bone metabolic markers are summarized in Figs. 1B-1D. Alkaline phosphatase (ALP) at the 1st wk showed a minimal increase of $146 \mathrm{U} / \mathrm{L}$ in the EG, compared with $127 \mathrm{U} / \mathrm{L}$ in the CG. This increasing trend continued in treated rats, reaching 1.7 times and 2.9 times at 3 and $6 \mathrm{wks}$, respectively, in contrast to control group values. Tartrate-resistant acid phosphatase (TRAP) values showed a further $2.5 \mathrm{x}$ reduction, in contrast to $\mathrm{CG}$ values, in the 1 st wk, although, at the $3 \mathrm{rd} w \mathrm{w}$, there was a $4 \mathrm{x}$ increase compared with CG values, and a decrease at the 6th wk to $2.3 \mathrm{U} /$ $\mathrm{L}$ values, but still 1.7x relative to $\mathrm{CG}$ values. However, there was no statistically significant difference in ALP and TRAP levels between the experimental and control groups. Plasma calcium levels in the EG increased through all the study periods, relative to decreasing Ca ion renal excretion. Data subjected to statistical analysis showed a significant difference between groups, in serum calcium levels at all periods ( $\mathrm{p}=0.01,0.02$, and 0.04 , respectively) as well as in urine calcium at $6 \mathrm{wks}(\mathrm{p}=0.04)$.

\section{Soft X-ray in high-resolution films}

Soft $x$-ray images from CZD, 1, 3, and 6 wks post-surgery, from groups treated and not treated with rhPTH, showed similar 

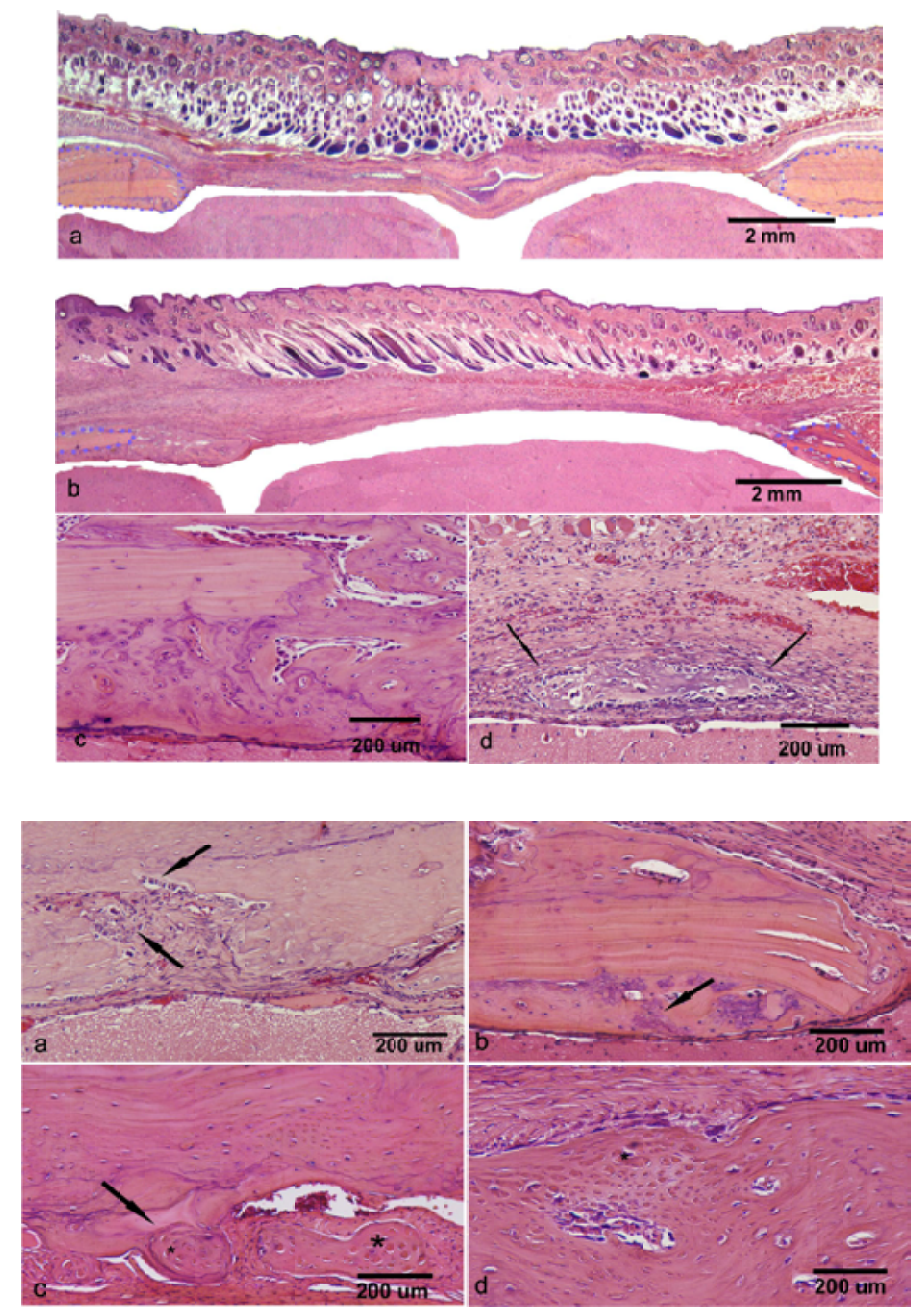

Figure 3. Histological analysis of critical-sized defect at 6 wks, with vehicle (A) or rhPTH treatment (B) at low magnification (6x, $7 \mathrm{x}$, bar $=2 \mathrm{~mm})$. The defect margins are depicted by blue dashes. From EG (Experimental group), a high-magnification (80x, bar = $200 \mathrm{im}$ ), woven bone formation can be seen on the edges (C), and ossicle (arrows) is covered by lining cells and a few osteoblasts in fibrous connective tissue with stromal cells (D) on H\&E-stained sections.

Figure 4. Bone hyperostosis lesions by rhPTH. (A) Focal osteoblast hyperplasia on endocortical surfaces (arrow) showing many active osteoblasts. Osteoclasts were surrounded by spindleshaped stromal cells (arrow), with fibrous connective tissue and congestive vessels. EG, $1^{\text {st }}$ wk. H\&E. Magnification 80x, bar = $200 \mu \mathrm{m}$. (B) On pre-existing parietal bone, new cortical formation was deposited in swirling cemental basophilic lines resembling disrupted mineralization. EG, $3^{\text {rd }}$ wks. H\&E. Magnification 80x, bar $=200 \mu \mathrm{m}$. (C, D) Hyperostosis showing periosteal and endosteal bone formed and organized in looping or networking pattern (arrow). Osteocytes demonstrated marked eosinophilia (asterisk) and some absent nuclei. EG, $6^{\text {th }}$ wks. H\&E. Magnification 80x, bar $=200 \mu \mathrm{m}$. results: rounded radiolucent areas on parietal bone, representing CZD healing by fibrous connective tissue. There were some internal radiopacities, which increased in size and numbers throughout the study, especially in the EG (Figs. 2A, 2B).

\section{Histopathology and histometric observations}

In the control group, at the 1st wk post-surgery, the defect area exhibited granulation tissue and congestion in the superior sagittal sinus. At the 3rd and 6th wks, the CZD area showed fibrous connective tissue healing. In all 3 periods, there was almost no regenerated bone in the defects except in the immediate vicinity of the surgical margins (Fig. 3A). In the experimental group, at the $1 \mathrm{st}$ wk, the CZD area showed granulation tissue and congestion of the superior sagittal sinus, as in the CG (Fig. 3B). At the edges, the bone formed showed swirling cemental basophilic lines resembling disrupted mineralization (Fig. 3C).

Osteosclerosis was observed with cortical bone apposition on existing surfaces. Focal osteoblast hyperplasia was found on parietal bone surfaces, showing many active osteoblasts without connections to osteoclasts. Limited focal proliferation of spindle- shaped stromal cell areas with fibrous connective tissue and vessels was observed (Fig. 4A). Within the critical-sized defect area, rare woven bone islands were detected, covered with many lining cells surrounded by fibrous connective tissue with stromal cells, socalled 'fibrous osteodystrophy' (Fig. 3D). At the 3rd and 6th wks, there was a significant increase $(p=0.01$ and 0.02 , respectively) in bone thickness, and many sutures were healed. Disrupted mineralization was also observed (Fig. 4B). Periosteal and endosteal bone formation organized in a looping or networking pattern was diagnosed as hyperostosis (Fig. 4C). Osteocytes from new bone or pre-existing bone were prominent, granular, and eosinophilic, showing intracellular hyaline body formation (IHB) and cell death (Fig. 4D).

The Table shows the results of histometric analysis. The new bone formed in the EG at $1 \mathrm{wk}(0.20 \% \pm 0.02)$ and $3 \mathrm{wks}(0.65 \%$ $\pm 0.02)$, compared with that formed in the $\mathrm{CG}(0.14 \% \pm 0.1$ and $0.40 \% \pm 0.2$, respectively), showed no significant statistical differences. At $6 \mathrm{wks}$, the EG showed significant bone formed $(2.81 \% \pm 0.6)$ compared with the CG $(1.06 \% \pm 0.2)(\mathrm{p}=0.023)$. 
María V. Jammal et al.: Bone Formation on CZD by rhPTH 1-34

Table. New bone volume and cortical thickness

\begin{tabular}{|c|c|c|c|c|}
\hline \multirow[t]{2}{*}{ Week } & \multicolumn{2}{|c|}{ Bone Volume } & \multicolumn{2}{|c|}{ Thickness } \\
\hline & $\mathrm{C} \mathrm{G}$ & EG & CG & EG \\
\hline $1^{\text {st }}$ & $0.14 \% \pm 0,1$ & $0.20 \% \pm 0.02$ & $16 \mu \mathrm{m} \pm 0,01$ & $20 \mu \mathrm{m} \pm 0.3$ \\
\hline & \multicolumn{2}{|c|}{$(p=0.7)$} & \multicolumn{2}{|c|}{$(p=0.51)$} \\
\hline $3^{\text {rd }}$ & $0.40 \% \pm 0.2$ & $0,65 \% \pm 0.02$ & $20 \mu \mathrm{m} \pm 0.02$ & $60 \mu \mathrm{m} \pm 9$ \\
\hline & \multicolumn{2}{|c|}{$(\mathrm{p}=0.6)$} & \multicolumn{2}{|c|}{$(\mathrm{p}=0,01)^{*}$} \\
\hline $6^{\text {th }}$ & $1.06 \% \pm 0.2$ & $2.81 \% \pm 0.02$ & $25 \mu \mathrm{m} \pm 0.5$ & $170 \mu \mathrm{m} \pm 8$ \\
\hline \multicolumn{3}{|c|}{$(p=0.023)^{*}$} & \multicolumn{2}{|c|}{$(p=0.02)^{*}$} \\
\hline
\end{tabular}

Mean and Standard Deviation Values at 1st, 3rd, and 6th wks from Control and Experimental Groups. New bone volume was expressed in $\%$, and cortical thickness was expressed in $\mu \mathrm{m}$. * $p<0.05$, MannWhitney test.

\section{Discussion}

Clinical and experimental evidence supports the use of recombinant human parathyroid hormone for severe osteoporosis treatment, based on anabolic success with daily administration. This led us to believe that rhPTH may also have an anabolic effect in other bone loss lesions. The potential of systemic intermittent rhPTH administration to promote bone regeneration in large defects is unknown.

We selected a well-established critical-size defect model ${ }^{11,12)}$ using rat calvaria bone, because its biological properties are similar to those of the human maxilla. Both are flat bones, with intramembranous ossification and two hard outer layer of cortical bone containing bone marrow. Further, CZD were selected because they are unable to undergo spontaneous bone regeneration. The results in a CZD rat model were obtained with a $20 \mu \mathrm{g} / \mathrm{kg} /$ day intermittent subcutaneous dose from 1 to $6 \mathrm{wks}$. We followed the regeneration process up to the sixth week to restrict the study to the maturity period of the animal, avoiding the old age phase during which the biological response is reduced. The doses were selected based on previous studies ${ }^{15,18)}$ where rhPTH 5-30 $\mu \mathrm{g} / \mathrm{kg} /$ day stimulated bone formation without side-effects. In our results, bone volume at edges and center of CZD in the EG was limited to $2.81 \pm 0.6 \%$ at the 6 th wk, while the value from the CG was 1.06 $\pm 0.2 \%$. Because bone formation was observed on defect perimeters, CZD regeneration did not occur. However, pre-existing bone thickness increased in all study periods, and was statistically significant at $3(\mathrm{p}=0.01)$ and $6(\mathrm{p}=0.02)$ wks. From these results, it is reasonable to consider that the slight bone formation around the CZD was based on the short rhPTH half-life ${ }^{7}$, enough to trigger pre-existing bone multicellular units ${ }^{19)}$, but insufficient to activate "determined osteoblasts" available in the dura mater ${ }^{20,21)}$. Rather than fully filling the bone defect, rhPTH generated few woven bone ossicles, surrounded by fusocellular lining cells in fibrous connective tissue that resembled fibrous osteodystrophy. Bone non-neoplastic proliferative lesions, like the focal osteoblast hyperplasia and focal stromal hyperplasia found in this research, have been previously described ${ }^{15,18,22)}$, but with high doses of rhPTH $(30,50$, and $75 \mu \mathrm{g} / \mathrm{kg} / \mathrm{day})$. This is the first report on the use of $\mathrm{rhPH}(20 \mu \mathrm{g} / \mathrm{kg} / \mathrm{day})$ for systemic treatment alone for CZD rats without any osteoconductive matrices, that formed a small amount of inductive new bone. The results of the present study seem to be in disagreement with those from the study of CZD animal models where PTH and some biomaterials were used ${ }^{13,14}$. In those studies, a significant amount of bone was formed, based on the osteoconductive ability of various bone replacements acting like a scaffold, and on the differences between whole PTH and recombinant hPTH biological action ${ }^{8)}$. Moreover, this is the first report showing non-proliferative forms of hyperostosis and osteopetrotic-like alterations at an rhPTH dose of $20 \mu \mathrm{g} / \mathrm{kg} /$ day. The diagnosis of non-proliferative hyperostosis was based on the following histopathologic lesions: bone sclerosis, closed suture space, disrupted mineralization, and periosteal-endosteal globular bone formation. New intracortical bone was organized in a looping or networking design. Based on AFIP guidelines, these considerations could be included as typicalatypical proliferative hyperostosis ${ }^{17)}$. Moreover, osteoblasts, osteocytes, and osteoclasts showed different sizes and shapes. The lacunar osteocytes showed many irregular shapes. Many presented an intracellular eosinophilic body resembling hyalinelike bodies (IHB), demonstrated by Roque's staining, acting as histological and potential markers of disease progression ${ }^{23)}$. Others showed some degree of autophagic cell death, shown by Sudan black staining. We considered that rhPTH produced stress toxicity on bone cells, forming from IHB to cell death ${ }^{24)}$. This could explain why many osteocytes apparently experienced an autophagic, caspase-independent, "type II" cell death, as observed by immunohistochemistry, and also possibly explained the increase in bone mass. In conclusion, systemic administration of rhPTH induced a small amount of new bone and acted aggressively on bone cells. Also, $20 \mu \mathrm{g} / \mathrm{Kg} /$ day produces protein damage or injury, 
a possible reason for programmed cell death (type I, II, or III) (Kroemer et al. 2009 ${ }^{25)}$, and may determine bone non-neoplastic proliferative lesions with disrupted mineralization.

\section{Acknowlegedments}

This study was supported by grants from CIUNT (Project $\mathrm{N}^{\circ}$ 26/J413) and CONICET. and Japan Society for the Promotion Science(JSPS) (Grant Number 23592990 and 24659891). We thank Mrs. María Lilia Romano for technical assistance. All authors state that they have no conflicts of interest.

\section{References}

1. Bilezikian J, Rubin M.and Finkelstein, J. Parathyroid hormone as an anabolic therapy for women and men. Journal of Endocrinological Investigation 28: 41-49. 2005

2. Pettway G, Megank J, Koh A, Feller E, Goldstein S and McCauley L. Parathyroid hormone mediates bone growth through the regulation of osteoblast proliferation and differentiation. Bone 42: 806-818. 2008

3. Dobnig $\mathrm{H}$ and Turner R. Evidence that intermittent treatment with parathyroid hormone increases bone formation in adult rats by activation of bone lining cells. Endocrinology 136: 3632-3638. 1995

4. Onyia J, Bidwell J, Herring J, Hulman J and Hock J. In vivo, human parathyroid hormone fragment (hPTH 1-34) transiently stimulates immediate early response gene expression, but not proliferation, in trabecular bone cells of young rats. Bone 17: 479-484. 1995

5. Centrella M, McCarthy T and Canalis E. Parathyroid hormone modulates transforming growth factor beta activity and binding in osteoblast-enriched cell cultures from fetal rat parietal bone. Proceedings of the National Academy of Sciences of the United States of America 85: 5889-5893. 1988

6. Bikle D and Wang Y. Insulin like growth factor-I: a critical mediator of the skeletal response to parathyroid tormone. Current Molecular Pharmacology Jun 25. [Epub ahead of print]. 2011

7. Hu Z, Niu H, Yang X, Li H, Sang G and Li B. Recombinant parathyroid hormone 1-34: pharmacokinetics, tissue distribution and excretion in rats. International Journal of Pharmaceutics 317: 144-154. 2006

8. Hodsman A, Bauer D, Dempster D, Dian L, Harris S, Kendler D, McClung M, Miller P, Olszynski W, Orwoll E. and Yuen C.K. Parathyroid hormone and teriparatide for the treatment of osteoporosis: a review of the evidence and suggested guidelines for its use. Endocrine Reviews 26: 688-703. (2005)

9. Nozaka K, Miyakoshi N, Kasukawa Y, Maekawa S, Noguchi $\mathrm{H}$ and Shimada $\mathrm{Y}$. Intermittent administration of human parathyroid hormone enhances bone formation and union at the site of cancellous bone osteotomy in normal and ovariectomized rats. Bone 42: 90-97. 2008

10. Komatsu D, Brune K, Liu H, Schmidt A, Han B, Zeng Q, Yang X, Nunes J, Lu Y, Geiser A, Ma Y, Wolos J, Westmore $\mathrm{M}$ and Sato M. Longitudinal in vivo analysis of the regionspecific efficacy of parathyroid hormone in a rat cortical defect model. Endocrinology 150: 1570-1579. 2009

11. Schmitz J P and Hollinger J O. The critical size defect as an experimental model for craniomandibular nonunions. Clinical Orthopaedics and Related Research 205: 299-308. 1986

12. Aybar A, Territoriale E. and Missana L. Animal model in calvaria to evaluate bone strategies. Acta Odontológica Latinoamericana 18: 21-25. 2005

13. Andreassen $\mathrm{T}$ and Cacciafesta V. Intermittent parathyroid hormone treatment enhances guided bone regeneration in rat calvarial bone defects. Journal of Craniofacial Surgery 15: 424-427. 2004

14. Yun J, Wikesjö U, Borke J, Bisch F, Lewis J, Herold R, Swiec G, Wood J and McPherson J. Effect of systemic parathyroid hormone (1-34) and a beta-tricalcium phosphate biomaterial on local bone formation in a critical-size rat calvarial defect model. Journal of Clinical Periodontology 37: 419-426. 2010

15. Vahle J, Sato M., Long G, Young J, Francis P, Engelhardt J, Westmore M, Linda Y. and Nold J. Skeletal changes in rats given daily subcutaneous injections of recombinant human parathyroid hormone (1-34) for 2 years and relevance to human safety. Toxicologic Pathology 30: 312-321. 2002

16. Jammal M, Territoriale E, Abate $\mathrm{C}$ and Missana L. High resolution films for bone regeneration evaluation. Acta Odontológica Latinoamericana 23: 33-36.

17. Long $P$, Leininge $J$, Nold $\mathbf{J}$ and Lieuallen W. Proliferative lesions of bone, cartilage, tooth and synovium in Rats. MST-2. In: Guides for toxicologic pathology. Washington, DC: STP/ARP/ AFIP, 1993 p. 1-3.

18. Vahle J, Long G, Sandusky G, Westmore M, Ma L and Sato M. Bone neoplasms in F344 rats given teriparatide (rhPTH 1-34) are dependent on duration of treatment and dose. Toxicologic Pathology 32: 426-438. 2004

19. Jilka R. (2007) Molecular and cellular mechanism of the anabolic effect of intermittent PTH. Bone 40: 1434-1446. 2010

20. Friedenstein AJ. Determined and inducible osteogenic precursor cells. In: Hand tissue growth repair and remineralization. Ciba Foundation Symposium. New series 11, 1973 p. 169-185.

21. Özcelik D, Turan T, Kabukcuoglu F, Ugurlu K, Ozturk O, Basak $\mathrm{M}$ and Bankaoglu, M. Bone induction capacity of the periosteum and neonatal dura in the setting of the rat zygomatic arch fracture model. Archives of Facial Plastic Surgery 5: 301-308. 2003 
María V. Jammal et al.: Bone Formation on CZD by rhPTH 1-34

22. Jollette J, Wilker C, Smith S, Doyle N, Hardisty J, Metcalfe A, Marriott T, Fox J and Wells D. Defining a noncarcinogenic dose of recombinant human parathyroid hormone 1-84 in a 2-year study in Fischer 344 rats. Toxicologic Pathology 34: 929-940. 2006

23. Zatloukal K, French S, Stumptner C, Strnad P, Harada M, Toivola D, Cadrin M and Bishr Omary M. From Mallory to Mallory-Denk bodies: what, how and why? Experimental Cell Research 313: 2033-2049. 2007

24. Harada M. Autophagy is involved in the elimination of intracellular inclusions, Mallory-Denk bodies in hepatocytes. Medical Molecular Morphology 43: 13-18. 2010

25. Kroemer G, Galluzzi L, Vandenabeele P, Abrams J, Alnemri E, Baehrecke E, Blagosklonny M, El-Deiry W, Golstein P, Green D, Hengartner M, Knight R, Kumar S, Lipton S, Malorni W, Nuñez G, Peter M, Tschopp J, Yuan J, Piacentini M, Zhivotovsky B and Melino G. Classification of cell death: Recommendations of the Nomenclature Committee on Cell Death. Cell Death \& Differentiation 16: 3-11. 2009 
J.Hard Tissue Biology Vol. 21(4):443-450, 2012 
